\title{
Neonatal Intensive Care: Is professional Status Related to Critical Bioethical Decision-Making?
}

\author{
Maria Dagla* \\ Department of Midwifery, University of West Attica, Greece \\ *Corresponding author: Maria Dagla, Department of Midwifery, University of West Attica, Greece, \\ Email: mariadagla@uniwa.gr
}

\section{ARTICLE INFO}

Received: 㓞 February 08, 2021

Published: 慧 February 15, 2021

Citation: Maria Dagla. Neonatal Intensive Care: Is professional Status Related to Critical Bioethical Decision-Making?. Biomed J Sci \& Tech Res 33(5)-2021. BJSTR. MS.ID.005471.

\begin{abstract}
When providing intensive care to extremely/very premature and/or diseased neonates, crucial moral dilemmas arise. The literature records a variety of approaches towards how bioethical decisions are made when it comes to choosing between the continuation of the intensive care provided or its withholding and withdrawal, in cases where it is not considered beneficial for the hospitalized neonate. The purpose of this mini review is to investigate whether the professional status of individuals/ healthcare professionals who make bioethical decisions on the provision of intensive care to neonates influences such a decision. As it turns out, there is a difference between neonatologists, midwives, and nurses in terms of how each occupational team perceives its responsibilities and role in such procedures in the clinical field.
\end{abstract}

Keywords: Neonatal Intensive Care; Bioethics, Decision-Making; Healthcare Professionals; Extremely Premature Neonate

\section{Introduction}

The bioethical dilemmas that arise concerning the provision of intensive care to premature or diseased neonates are among the ten most important ethical challenges in the field of health [1]. The role and attitude of healthcare professionals who make or participate in such critical ethical decisions, such as neonatologists, midwives, and nurses, is of particular interest. These healthcare professionals work in "sensitive" health facilities -delivery room, surgery department, Neonatal Intensive Care Unit (NICU)- and providing care to diseased and extremely/very premature neonates is part of their daily clinical practice. Research, however, has shown that the perception, evaluation, and treatment of bioethical issues vary between healthcare professionals, depending on the specific professional responsibilities and characteristics of each occupational team, as well as its role in dealing with such situations $[2,3]$.

Physicians (neonatologists), in particular, play a critical role in a, considerably, sensitive time period and, as has been documented, are mainly concerned about the making of the decision [2]. The responsibilities of doctors during this period extend from discussions with parents to the creation of a timetable for withholding or withdrawing treatment. Research indicates that most physicians tend to apply the principle of benefit to critical ethical decision-making regarding the provision of care to diseased and premature neonates [4].

For many European neonatologists, for example, the provision of intensive care and treatment is not considered an end, and the survival of the neonate is not the sole and exclusive goal of the care provided [5]. On the contrary, the issue of the quality of life of the neonate seems to be of particular concern to them [6,7], as they emphasize and focus on the incertitude of the provided care and treatment, and on the outcome [8]. Thus, based on empirical data, European neonatologists express their concern about the continuation of intensive care and recognize the need for its withdrawal in some cases $[2,9,10]$.

On the other hand, physicians tend to favor the practice of withholding treatment rather than withdrawing it [11]. This tendency is justified, in part, due to psychological factors, since, in the case of withdrawal, the doctor is considered responsible for the death of the patient; this does not hold in the case of withholding treatment, since death occurs more naturally [12]. However, as Streiner, et al. [13] observe, physicians tend to be more optimistic about the chances of survival and the long-term development of severe disabilities in the neonate than other healthcare professionals, such as nurses. Thus, physicians tend 
to recommend interventions that support life more than other healthcare professionals [14].

For other groups of healthcare professionals involved in the care of extremely/very premature and diseased neonates, such as midwives and nurses, the main concern is the fulfillment of their responsibilities [2]. These occupational groups tend to apply the principle of parental autonomy, which is why, when critical decisions need to be made, they give priority to fully informing the parents, considering their point of view quite important [4]. They often underline the suffering of the neonate, especially when there is little hope of recovery [2,8] and express their concern for the continuation of treatment in cases where the costs outweigh the benefits for the neonate $[2,15-17]$. At the same time, the longterm consequences for the quality of life of the neonate and the consequences that follow for the family are serious ethical issues for midwives [18].

Traditionally, midwives and nurses have the responsibility of providing comprehensive care to a diseased or premature neonate, including providing comfort and relief from pain. They play a key role in informing parents, encouraging and supporting them, as well as clarifying the information provided [19]. They consult with neonatologists and other healthcare professionals, while midwives, in particular, take part in informing the couples prenatally, when there is a risk of premature birth [20-22]. Their direct and longterm contact, communication and engagement with neonates and parents favors the establishment of trust, helps to reduce the distance between parents and healthcare professionals and, often, leads to an optimal understanding of the intentions of both parties and the minimization of misunderstandings. Their involvement in end-of-life clinical decisions is considered vital; they have been described as "advocates" of the neonate and the family [19], as they take part in the care and overall process until death comes, while guiding and supporting parents, mentally and morally, in those difficult times [12].

These healthcare professionals are not the experts who will make the final decision on the course of care and treatment provided; but because of their education, experience, and prolonged and continuous presence next to the neonate, they are able to understand the effects of the various decisions, understand the pain and suffering of the neonate and inform and interact with the parents. Thus, they contribute to the formation of a necessary context [23], which favors decision-making on the part of parents [19], as well as their active participation even in end-of-life decisionmaking processes $[24,25]$.

Ethical dilemmas associated with the care of premature and diseased neonates are part of the everyday clinical practice in NICUs. These dilemmas arise at the international level, but at the same time, are shaped by specific strategies, conditions and practices applied in treatment and neonatal intensive care, and which differ both between countries and between NICUs in each country $[5,8,26,27]$. At the same time, the professional characteristics of healthcare professionals further contribute to the existence of diversification in the treatment of critical cases in the NICU. According to the international literature, such diversification, which contributes to the formation of different professional and ethical standards on the part of experts, is exacerbated by the observed lack of a relevant legal and institutional framework [7]. In addition, cultural parameters related to the organization, structure and operation of the national health system of each country during the perinatal period seem to have a significant impact on shaping the attitude of healthcare professionals towards bioethical issues related to neonatal care [27].

Based on the above, it can be concluded that the process of critical bioethical decision-making, immediately after birth and during the hospitalization of the neonate in the NICU, is particularly crucial and depends on various medical, cultural, ethical, and institutional factors. The professional status of the healthcare professional taking part in such bioethical decisions seems to influence the final decision that will be made for the extremely premature and/or diseased neonate.

\section{References}

1. Baskett PJ, Lim A (2004) The varying ethical attitudes towards resuscitation in Europe. Resuscitation 62: 267-273.

2. Epstein EG (2010) Moral obligations of nurses and physicians in neonatal end-of-life care. Nurs Ethics 17: 577-589.

3. Hov R, Hedelin B, Athlin E (2007) Being an intensive care nurse related to questions of withholding or withdrawing curative treatment. J Clin Nurs 16(1): 203-211.

4. Guardione R, Boano E, Di Maio P, Catarinella A, Romano C (2011) Nurses' ethical problems in the care of extremely low birth weight infants. Early Human Development 87: 85-86.

5. Rebagliato M, Cuttini M, Broggin L, Berbik I, de Vonderweid U, et al. (2000) Neonatal end-of-life decision making: Physicians' attitudes and relationship with self-reported practices in 10 European countries. JAMA 15 284(19): 2451-249.

6. Verhagen E, Sauer PJJ (2005) The Groningen Protocol - Euthanasia in Severely Ill Newborns. N Engl J Med 10: 959-962.

7. Provoost V, Cools F, Mortier F, Bilsen J, Ramet J, et al. (2005) Medical end-of-life decisions in neonates and infants in Flanders. Lancet 9-15 365(9467): 1315-1320.

8. van Zuuren FJ, van Manen E (2006) Moral dilemmas in neonatology as experienced by health care practitioners: A qualitative approach. Med Health Care Philos 9: 339-347.

9. Hazebroek FW (2006) Quality improvement in pediatric surgery: the Rotterdam experience. J Pediatr Surg 41: 617-623.

10. Cuttini M, Nadai M, Kaminski M, Hansen G, de Leeuw R, et al. (2000) Endof-life decisions in neonatal intensive care: physicians' self-reported practices in seven European countries. Lancet 355: 2112-2118.

11. Puntillo KA, McAdam JL (2006) Communication between physicians and nurses as a target for improving end-of-life care in the intensive care unit: challenges and opportunities for moving forward. Crit Care Med 34 (Suppl 11): 332-340.

12. Devictor D, Latour JM, Tissieres P (2008) Forgoing Life-Sustaining or Death-Prolonging Therapy in the Pediatric ICU. Pediatr Clin N Am 55: 791-804. 
13. Streiner DL, Saigal S, Burrows E, Stoskopf B, Rosenbaum P (2001) Attitudes of parents and health care professionals toward active treatment of extremely premature infant. Pediatrics 108: 152-157.

14. Orzalesi M, Cuttini M (2005) Ethical considerations in neonatal respiratory care. Biol Neonate 87(4): 345-353.

15. Hamric AB, Blackhall LJ (2007) Nurse-physician perspectives on the care of dying patients in intensive care units: collaboration, moral distress, and ethical climate. Crit Care Med 35 2: 422-429.

16. Corley MC, Minick P, Elswick RK, Jacobs M (2005) Nurse moral distress and ethical work environment. Nurs Ethics 12: 381-390.

17. Gutierrez KM (2005) Critical care nurses' perceptions of and responses to moral distress. Dimens Crit Care Nurs 24: 229-241.

18. Garel M, Seguret S, Kaminski M, Cuttini M (2004) Ethical decisionmaking for extremely preterm deliveries: results of a qualitative survey among obstetricians and midwives. J Matern Fetal Neonatal Med 15: 394-399.

19. Kavanaugh K, Moro TT, Savage TA (2010) How Nurses Assist Parents Regarding Life Support Decisions for Extremely Premature Infants. J Obstet Gynecol Neonatal Nurs 39(2): 147-158.

20. Bastek TK, Richardson DK, Zupancic JA, Burns JP (2005) Prenatal consultation practices at the border of viability: a regional survey. Pediatrics 116(2): 407-413.

\section{ISSN: 2574-1241}

DOI: 10.26717/BJSTR.2021.33.005471

Maria Dagla. Biomed J Sci \& Tech Res

(C) (P) This work is licensed under Creative

Submission Link: https://biomedres.us/submit-manuscript.php
21. Keenan HT, Doron MW, Seyda BA (2005) Comparison of mothers' and counselors' perceptions of predelivery counseling for extremely premature infants. Pediatrics 116(1): 104-111.

22. Martinez AM, Partridge JC, Yu V, Wee Tan K, Yeung CY, et al. (2005) Physician counselling practices and decision-making for extremely preterm infants in the Pacific Rim. J Paediatr Child Health 41(4): 209 214.

23. Rushton $\mathrm{CH}$ (2005) A framework for integrated pediatric palliative care: being with dying. J Pediatr Nurs 20(5): 311-325.

24. McHaffie HE, Laing IA, Parker M, McMillan J (2001) Deciding for imperilled newborns: medical authority or parental autonomy? J Med Ethics 27(2): 104-109.

25. Wocial LD (2000) Life support decisions involving imperiled infants. J Perinat Neonatal Nurs 14(2): 73-86.

26. Trevisanuto D, Doglioni N, Ferrarese P, Bortolus R, Zanardo V (2006) Neonatal resuscitation of extremely low birthweight infants: a survey of practice in Italy. Arch Dis Child Fetal Neonatal Ed 91: 123-124.

27. Habiba M, Kaminski M, Da Frè M, Marsal K, Bleker O, et al. (2006) Caesarean section on request: a comparison of obstetricians' attitudes in eight European countries. BJOG 113(6): 647-656.

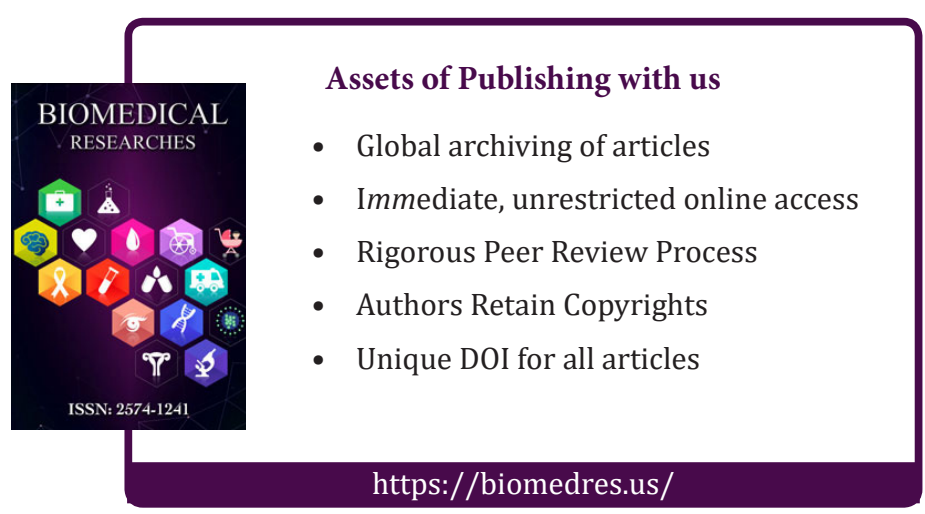

